\title{
The effect of clopidogrel on platelet activity in patients with and without type-2 diabetes mellitus: a comparative study
}

Claudia Schuette ${ }^{\dagger}$, Daniel Steffens ${ }^{\dagger}$, Marco Witkowski, Caroline Stellbaum, Peter Bobbert, Heinz-Peter Schultheiss and Ursula Rauch

\begin{abstract}
Background: Although antiplatelet therapy involving clopidogrel is a standard treatment for preventing cardiovascular events after coronary stent implantation, patients can display differential responses. Here, we assessed the effectiveness of clopidogrel on platelet function inhibition in subjects with and without type-2 diabetes and stable coronary artery disease. In addition, we investigated the correlation between platelet function and routine clinical parameters.

Methods: A total of 64 patients with stable coronary heart disease were enrolled in the study. Among these, 32 had known type-2 diabetes, whereas the remaining 32 subjects were non-diabetics (control group). A loading dose of $300 \mathrm{mg}$ clopidogrel was given to clopidogrel-naïve patients (13 patients in the diabetes group and 14 control patients). All patients were given a daily maintenance dose of $75 \mathrm{mg}$ clopidogrel. In addition, all patients received $100 \mathrm{mg}$ ASA per day. Agonist-induced platelet aggregation measurements were performed on hirudin-anticoagulated blood using an impedance aggregometer (Multiple Platelet Function Analyzer, Dynabyte, Munich, Germany). Blood samples were drawn from the antecubital vein $24 \mathrm{~h}$ after coronary angiography with percutaneous coronary intervention. The platelets were then stimulated with ADP alone or ADP and prostaglandin-E (ADP and ADP-PGE tests, respectively) in order to evaluate clopidogrel-mediated inhibition of platelet function. The effectiveness of ASA was measured by stimulation with arachidonic acid (ASPI test). In addition, maximal platelet aggregation was assessed via stimulation with thrombin receptor-activating peptide (TRAP test).
\end{abstract}

Results: Patients with diabetes exhibited significantly less inhibition of platelet function than patients without diabetes (ADP-PGE test $p=0.003$; ASPI test $p=0.022$ ). Administering a clopidogrel loading dose of $300 \mathrm{mg}$ did not result in a lower level of ADP-PGE-induced platelet reactivity in comparison to the use of a $75 \mathrm{mg}$ maintenance dose. Moreover, we observed that ADP-PGE-induced platelet inhibition was positively correlated with fasting blood glucose and $\mathrm{HbA1c}$ $(p<0.01)$.

Conclusions: Patients with type-2 diabetes exhibited increased platelet reactivity compared to patients without diabetes despite combined treatment with clopidogrel and ASA. Using a loading dose of clopidogrel rather than small daily doses was not sufficient for adequately overcoming increased platelet reactivity in patients with type-2 diabetes, highlighting the need for more effective anti-platelet drugs for such patients.

Keywords: Clopidogrel, Diabetes, Platelet function, Ccoronary heart disease, Percutaneous coronary intervention

\footnotetext{
* Correspondence: ursula.rauch@charite.de

${ }^{\dagger}$ Equal contributors

Department of Internal Medicine/Cardiology, Campus Benjamin Franklin,

Charité - Universitätsmedizin Berlin, Hindenburgdamm 30, 12200 Berlin,

Germany
}

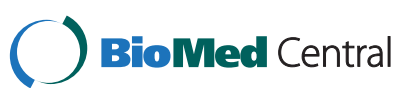

(c) 2015 Schuette et al.; licensee BioMed Central. This is an Open Access article distributed under the terms of the Creative Commons Attribution License (http://creativecommons.org/licenses/by/4.0), which permits unrestricted use, distribution, and reproduction in any medium, provided the original work is properly credited. The Creative Commons Public Domain Dedication waiver (http://creativecommons.org/publicdomain/zero/1.0/) applies to the data made available in this article, unless otherwise stated. 


\section{Background}

Combined antiplatelet therapy using acetylsalicylic acid (ASA) and clopidogrel is the standard therapy regimen for secondary prevention of cardiovascular events after coronary stent implantation in patients with stable coronary artery disease [1-3]. However, variable inter- and intra-individual responses to clopidogrel (i.e., "clopidogrel low responsiveness") represent a significant clinical limitation [4,5]. In addition, various drug interactions have been reported to affect clopidogrel-mediated inhibition of platelet function [6-8]. Notably, inefficient suppression of platelet activity upon treatment with clopidogrel and ASA has been associated with significantly increased cardiovascular risk $[9,10]$.

In 2000, we reported that shear-stress-induced thrombus formation on the tunica media of an injured blood vessel was significantly increased when blood was obtained from patients with type-2 diabetes as compared to nondiabetics [11]. Moreover, we found that hyperglycemia and leukocyte count positively correlated with increased thrombus formation [11], and that intensive glycemic control in patients with type-2 diabetes was effective in decreasing blood thrombogenicity [12]. We also demonstrated that diabetic cardiovascular autonomic neuropathy and diabetic angiopathy were associated with increased platelet activation, possibly contributing to the pathogenesis of these conditions [13,14]. Additionally, it has previously been shown that mean platelet volume increases with increasing fasting blood glucose [15]. Thus, these alterations may collectively contribute to the association between poor glycemic control and poor outcome in patients undergoing percutaneous coronary intervention [16].

The response of patients with type-2 diabetes to anti-aggregatory therapy has therefore recently become an important topic of investigation. Indeed, Geisler et al. studied the effect of a $600 \mathrm{mg}$ clopidogrel loading dose in patients with acute coronary syndrome with or without type-2 diabetes [17]. They reported that diabetic patients displayed a significantly higher risk for further atherothrombotic complications resulting from insufficient inhibition of platelet aggregation, and increased blood thrombogenicity. In addition, Angiolillo et al. found that clopidogrel withdrawal is associated with an increase in platelet and inflammatory biomarkers in diabetic patients [18].

In the present study, we examined the effect of combined treatment with clopidogrel and ASA on platelet function inhibition using impedance aggregometry. We compared agonist-induced platelet aggregation in patients with stable coronary artery disease with and without type-2 diabetes. Moreover, we evaluated the correlation between metabolic parameters and measures of platelet function.

\section{Methods}

\section{Patients and anti-platelet medication strategies}

This study included 64 consecutively enrolled patients with coronary heart disease and stable angina pectoris. Patients were included if they were aged 40 to 75 years, were receiving a statin along with ASA, and had been selected to undergo clopidogrel treatment at the discretion of their physician. Patients were excluded if they had experienced a myocardial infarction within the last 28 days; displayed elevation in troponin $\mathrm{T}$ or creatinine kinase; had been receiving long-term anticoagulation therapy; had known cancer, liver cirrhosis, or dialysisdependent renal failure; were receiving antibiotic therapy; were pregnant; or were alcohol-dependent. Among the enrolled subjects, 32 patients had a confirmed diagnosis of type- 2 diabetes and 32 patients were diabetes free. An oral glucose tolerance test was employed to exclude the presence of diabetes in the control group. The patient characteristics, concurrent medications, and laboratory blood test results are given in Table 1. All

\section{Table 1 Patient characteristics}

\begin{tabular}{|c|c|c|}
\hline & $\begin{array}{l}\text { Control } \\
(n=32)\end{array}$ & $\begin{array}{l}\text { Diabetes } \\
(n=32)\end{array}$ \\
\hline Age (y) & $64.8 \pm 12.5$ & $70.2 \pm 8.2$ \\
\hline Sex (\% women) & 21.9 & 21.9 \\
\hline Platelets (nl) & $248.5 \pm 89.4$ & $223.0 \pm 75.4$ \\
\hline BMl $\left(\mathrm{kg} / \mathrm{m}^{2}\right)$ & $25.5 \pm 3.2$ & $30.0 \pm 5.4$ \\
\hline Leucocytes (nl) & $6.9 \pm 1.8$ & $7.5 \pm 2.5$ \\
\hline $\mathrm{HbA1c}(\%)$ & $5.6 \pm 0.3$ & $7.2 \pm 1.2$ \\
\hline Fasting blood glucose (mg/dl) & $84 \pm 16.0$ & $151 \pm 33.1$ \\
\hline CRP (mg/dl) & $0.6 \pm 1.5$ & $0.8 \pm 1.7$ \\
\hline Cholesterol (mg/dl) & $160 \pm 33.5$ & $157 \pm 39.3$ \\
\hline Triglycerides (mg/dl) & $150 \pm 69.9$ & $165 \pm 51.2$ \\
\hline HDL-cholesterol (mg/dl) & $45.8 \pm 11.3$ & $46.8 \pm 18.9$ \\
\hline LDL-cholesterol (mg/dl) & $95.1 \pm 24.1$ & $98.2 \pm 28.8$ \\
\hline \multicolumn{3}{|l|}{ Concomitant drugs } \\
\hline Statin (\%) & 96.9 & 100 \\
\hline CCB (\%) & 90.1 & 65.6 \\
\hline ASA-100 mg/d (\%) & 100 & 100 \\
\hline \multicolumn{3}{|l|}{ Antidiabetic drugs } \\
\hline Metformin (\%) & 0 & 59.4 \\
\hline Insulin (\%) & 0 & 31.3 \\
\hline Other/none (\%) & 0 & 25.0 \\
\hline \multicolumn{3}{|l|}{ Clopidogrel } \\
\hline Loading dose-300 mg (\%) & 43.8 & 40.6 \\
\hline Maintenance dose-75 mg/d (\%) & 100 & 100 \\
\hline
\end{tabular}

Legend: BMI, body mass index; HbA1c, glycated hemoglobin; CRP, C-reactive protein; $\mathrm{HDL}$, high-density lipoprotein; $L D L$, low-density lipoprotein; $C C B$, calcium channel blocker; ASA, acetylsalicylic acid. 
patients received $100 \mathrm{mg}$ of ASA (uncoated) once daily. In the control group, 18 patients received $75 \mathrm{mg}$ of clopidogrel once daily; in the diabetes group, 19 received $75 \mathrm{mg}$ of clopidogrel once daily. The day prior to undergoing percutaneous coronary intervention (PCI), a $300 \mathrm{mg}$ loading dose of clopidogrel was given to the 14 clopidogrel-naïve patients in the control group and the 13 in the diabetes group. Subsequently, all 64 patients were administered a maintenance dose of $75 \mathrm{mg}$ clopidogrel per day. All patients received unfractionated heparin (UFH) during the catheterization. Platelet function was measured in all patients $24 \mathrm{~h}$ after coronary angiography and PCI (Figure 1). This study was approved by the local ethics committee, and all patients gave informed consent prior to study inclusion.

\section{Assessing inhibition of platelet function}

Venous blood was collected in test tubes containing hiru$\operatorname{din}(25 \mu \mathrm{g} / \mathrm{ml})$, which allowed for inhibition of coagulation without affecting calcium levels. Platelet function was then analyzed using a Multiple Platelet Function Analyzer (Multiplate-Test, Dynabyte, Munich, Germany), which measures increases in impedance [19]. In brief, activated platelets adhere to sensor surfaces within the system and aggregate to form a barrier, which results in a constant increase in resistance between the electrodes. The extent of aggregation was measured over a period of $6 \mathrm{~min}$ and was calculated based on the area under the curve (AUC) [20]. Whole blood was first diluted with $0.9 \% \mathrm{NaCl}$ at a ratio of 1:1 and then stored for $3 \mathrm{~min}$ in the test cell at $37^{\circ} \mathrm{C}$. Subsequently, several reagents were added to induce platelet aggregation: 1) adenosine diphosphate (ADP, final concentration: $6.4 \mu \mathrm{mol} / \mathrm{l}$ ) for assessment of ADP-dependent platelet aggregation; 2) ADP and prostaglandin-E (ADPPGE, $6.4 \mu \mathrm{mol} / \mathrm{l}$ ) for measuring the effectiveness of the P2Y12-receptor antagonist clopidogrel; 3) arachidonic acid $(0.5 \mathrm{mmol} / \mathrm{l}$, ASPI test) for evaluating the effectiveness of ASA on platelet function; and 4) thrombin receptoractivating peptide (TRAP; final concentration: $32 \mu \mathrm{mol} / \mathrm{l}$ ) for stimulating thrombin receptors on platelets to induce maximal platelet aggregation.

\section{Definition of low responsiveness to clopidogrel}

ADP-induced platelet aggregation as measured by impedance aggregometry has been shown to correlate well with that measured using the vasodilator-stimulated phosphoprotein (VASP) phosphorylation test, which is considered to be the gold standard for detecting clopidogrel low responders [21]. Based on this prior comparison by Stellbaum et al., we pre-defined clopidogrel lowresponders as those with platelet aggregation above the 75th percentile (cut-off of 27 AUC for the ADP test or 10 AUC for the ADP-PGE test; data not shown).

\section{Statistical methods}

As there were no comparable studies that could be used to obtain effect sizes at the time of designing the study, no power analysis for sample size calculation could be carried out. Therefore, we aimed to enroll at least $\mathrm{n} 1=\mathrm{n} 2=30$ patients in both groups to ensure the proper conduct of parametric test statistics (i.e. robustness against violations of the assumptions of normality and variance homogeneity) to obtain the associated sensitivity.

To test for significant differences between the two groups a Student's t-test for independent samples was used. In case of subsequent analyses with smaller and/or unequal sample sizes, we used the Mann-Whitney test statistic. To test for significant correlations, Pearson's correlation coefficient was calculated and tested for significance as this test statistic reacts robustly to violations of the assumed bivariate normal distribution when tested against a null hypothesis of $\rho=0$. All reported probability values are two-sided, and a value of $\mathrm{p}<0.05$ was considered to indicate statistical significance. Statistical analyses were carried out using SPSS software, version 16.0 for windows (SPSS, Inc., Chicago, IL, USA).

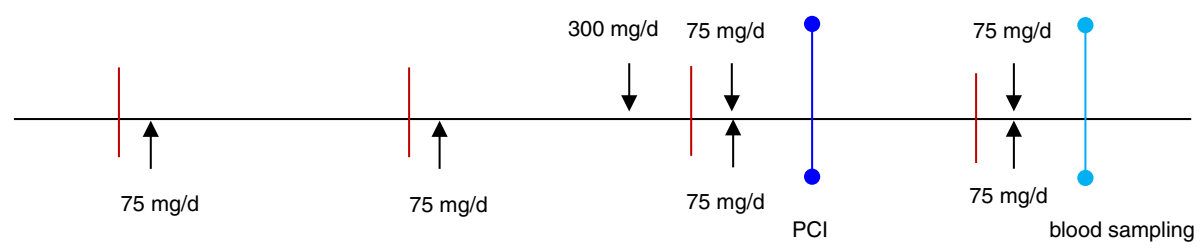

Patients on maintenance clopidogrel

Figure 1 Clinical study design. Legend: Schematic representation of the study design. Patients presenting stable coronary heart disease with or without type-2 diabetes were enrolled. A $300 \mathrm{mg}$ loading dose of clopidogrel was given to clopidogrel-naive patients. All other patients were given a daily maintenance dose of $75 \mathrm{mg}$ clopidogrel. In addition, all patients received acetylsalicylic acid (ASA; $100 \mathrm{mg} /$ day). Blood samples were drawn $24 \mathrm{~h}$ after coronary angiography with percutaneous coronary intervention (PCI), and agonist-induced platelet aggregation measurements were performed. 


\section{Results}

In the present study, we enrolled 64 patients with stable coronary heart disease. Among them, 32 had known type- 2 diabetes, whereas the remaining 32 subjects were non-diabetics (control group). The characteristics of these patients are presented in Table 1.

ADP- and ADP-PGE-induced platelet reactivity was found to be significantly higher in patients with type-2 diabetes compared to control patients, despite treatment with clopidogrel and ASA (Figure 2; ADP test: $\mathrm{p}=0.003$; ADP-PGE test: $\mathrm{p}=0.004)$. Notably, $31 \%$ of the patients with type-2 diabetes exhibited ADP-induced platelet reactivity above 27 AUC, which was defined as clopidogrel low responsiveness. In contrast, only $6.4 \%$ of the patients without diabetes were classified as low responders (Figure 2A).

Considering TRAP-induced platelet reactivity, there was significantly higher platelet reactivity observed in the diabetes group when compared to non-diabetic patients (Figure 3, $\mathrm{p}<0.05$ ). In line with this, arachidonic acid-induced platelet reactivity (ASPI test) was significantly elevated in patients with diabetes (Figure 4, $\mathrm{p}=0.01)$.

When comparing platelet aggregation in both groups after administration of a clopidogrel loading dose (300 mg), patients with type-2 diabetes continued to exhibit significantly higher ADP- and ADP-PGE-induced platelet reactivity compared to patients without diabetes (Figure 5A).

Finally, we observed that ADP-PGE-induced platelet aggregation positively correlated with fasting blood glucose $(\mathrm{r}=0.37 ; \mathrm{p}<0.001)$ and HbA1c level $(\mathrm{r}=0.36$; $\mathrm{p}<0.005)$.

\section{Discussion}

Our findings indicate that combined treatment with clopidogrel and ASA is less effective in patients with type-2

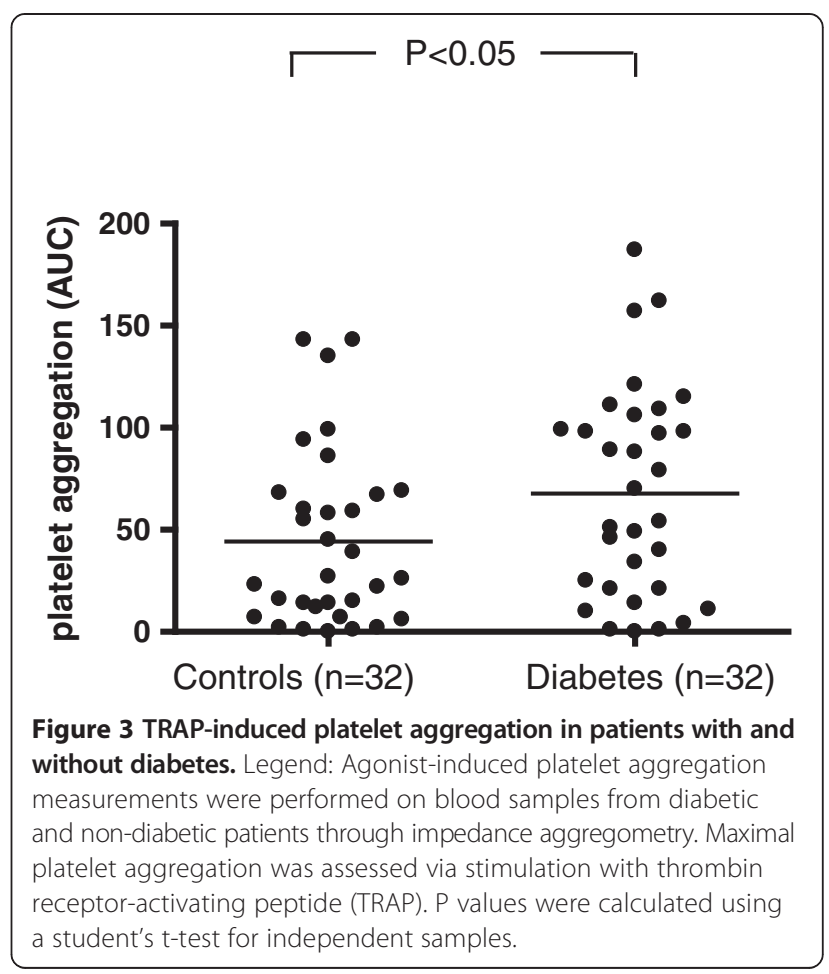

diabetes than in those without. It is clear from the literature that there are many different factors that can have an effect on platelet reactivity in diabetic patients. Mortensen et al. found that diabetic patients with coronary heart disease displayed higher levels of sP-selectin than did non-diabetics, indicating increased platelet reactivity and higher cardiovascular risk [22]. A study by Erlinge et al. demonstrated that decreased response to clopidogrel by diabetic patients was likely due to a reduction in the amount of circulating active metabolite [23]. This indicates inefficient transformation of clopidogrel into the active metabolite in diabetics; however, the exact reason
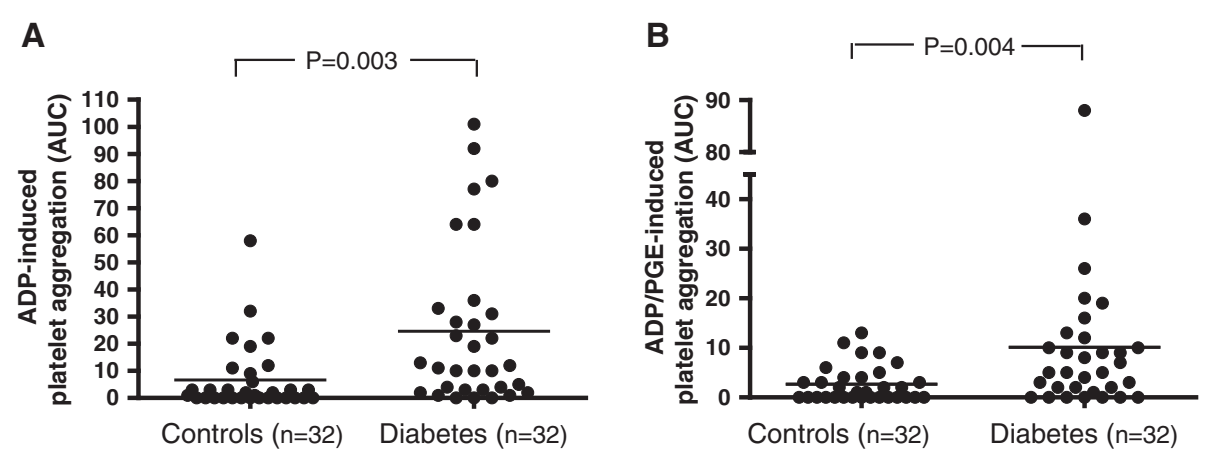

Figure 2 ADP- and ADP-PGE -induced platelet aggregation in patients with and without diabetes. Legend: Agonist-induced platelet aggregation measurements were performed on blood samples from diabetic and non-diabetic patients using an impedance aggregometer. The platelets were stimulated with adenosine diphosphate (ADP; $\mathbf{A}$ ) alone or ADP and prostaglandin-E (ADP-PGE; B). P values were calculated using a student's t-test for independent samples. 


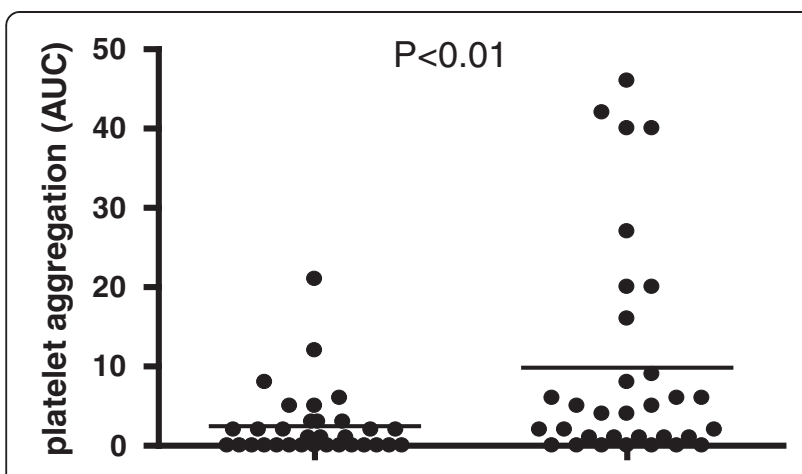

$$
\text { Controls }(n=32) \quad \text { Diabetes }(n=32)
$$

Figure 4 ASPI test in patients with and without diabetes. Legend: Platelet aggregation measurements were performed on blood samples from diabetic and non-diabetic patients using an impedance aggregometer. The effectiveness of acetylsalicylic acid (ASA) was measured by stimulation with arachidonic acid (ASPI test). P values were calculated using a student's t-test for independent samples.

for this remains unclear. The increased cardiovascular risk in patients with type- 2 diabetes has been shown to be related to higher levels of certain inflammatory markers [24,25]. Geisler et al. reported that diabetic patients with hyperglycemia had increased amounts of such markers in comparison to normoglycemics and non-diabetic patients [26]. Moreover, they showed that higher levels of inflammatory markers correlated with decreased response to ASA and clopidogrel dual therapy. Recently, Rosiak et al. reported decreases in a number of inflammatory markers in patients with type- 2 diabetes on either raising the daily dosage of ASA or replacing ASA with clopidogrel [27]. Furthermore, they found that the effects were reduced in patients with poor long term glycemic control. Higher esterase activity has been identified in patients with type- 2 diabetes in comparison to those without the condition. This has been speculated to be a cause of decreased efficacy of ASA therapy in diabetic patients [28]. Similarly, increased esterase activity in younger patients has been linked to reduced bioavailability of ASA, resulting in high platelet reactivity [29].

Although it is well accepted that platelet aggregation inhibition is necessary for patients with type-2 diabetes [30], there remains a need to develop more effective antiplatelet therapies [31]. Patients with diabetes are known to display increased populations of circulating platelets that express activation-dependent adhesion molecules that may contribute to increased aggregation and might provide new pharmacological targets [32]. Also, transient receptor potential canonical type 6 (TRPC6) calcium channels increase on platelets in response to high glucose [33], and could represent a novel target. Moreover, investigating the role of platelet-derived tissue factor-positive microparticles as well as adipose tissue-secreted hormones may be interesting with regard to therapeutic potential $[34,35]$. Indeed, leptin, resistin, and adiponectin have all been found to be increased in diabetic patients [35,36]. Thus, further research will be needed to assess these molecules as possible targets for novel antiplatelet therapies.

In addition, currently existing therapies could also be beneficial for diabetic patients. For example, we recently compared periprocedural platelet reactivity after administrating either bivalirudin, which directly binds to thrombin (the most effective activator of platelets), or unfractionated heparin during $\mathrm{PCI}$, finding that bivalirudin was better than heparin at reducing platelet activation [37]. Thus, the efficacy of bivalirudin could be tested in diabetic patients and compared to current treatment approaches. Moreover, ADP receptor inhibitors (other than clopidogrel) have been assessed for use in patients with diabetes. Indeed,
A

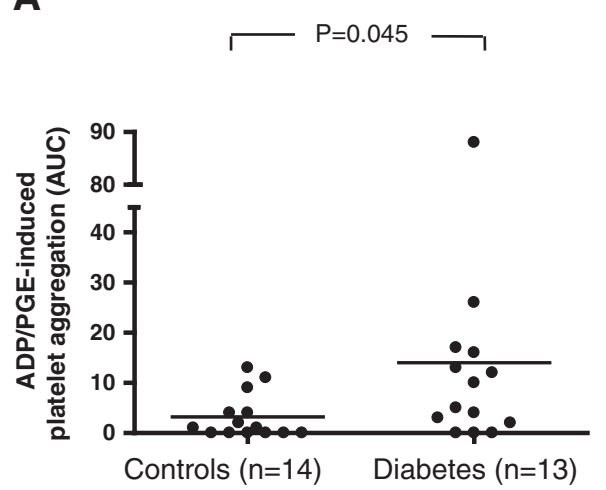

B

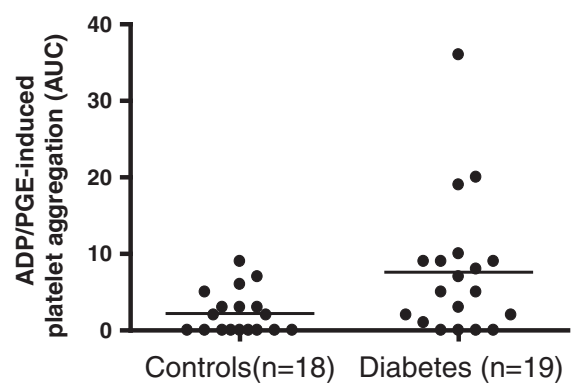

Figure 5 ADP/PGE-induced platelet aggregation after clopidogrel loading and maintenance doses in diabetic and non-diabetic patients. Legend: Agonist-induced platelet aggregation measurements were performed on blood samples through impedance aggregometry. The platelets were stimulated with adenosine diphosphate and prostaglandin (ADP-PGE) in order to evaluate clopidogrel-mediated inhibition of platelet function after a $300 \mathrm{mg}$ loading dose (A), and after a $75 \mathrm{mg}$ maintenance dose (B) in patients with and without diabetes. P values were calculated using a student's t-test for independent samples. 
recent randomized studies demonstrated that ticagrelor was superior to prasugrel for reducing platelet reactivity in subjects with acute coronary syndrome and diabetes $[38,39]$. However, whether this higher potency of ticagrelor will translate into a clinical benefit for diabetic patients remains to be investigated. Nevertheless, it is interesting that treatment with ticagrelor led to a significant reduction in the rate of death from vascular causes, myocardial infarction, or stroke when compared to clopidogrel in acute coronary syndrome patients [40].

In the present study, we demonstrated that even a $300 \mathrm{mg}$ loading dose of clopidogrel did not provide as effective platelet inhibition in patients with diabetes as that achieved in those without. Similar results were achieved by Angiolillo et al., who reported increased platelet reactivity in diabetic compared to non-diabetic patients, both after long term ASA/clopidogrel dual therapy and after a $300 \mathrm{mg}$ loading dose, prior to PCI [31]. However, Sibbing et al. used a higher loading dose of $600 \mathrm{mg}$, and found no significant difference in platelet reactivity between diabetic and non-diabetic patients [41]. Thus, a significant proportion of patients with type-2 diabetes could display an insufficient therapeutic effect when treated with long term daily clopidogrel doses of $75 \mathrm{mg}$ prior to PCI. A more recent study by Angiolillo et al. compared a $600 \mathrm{mg}$ loading dose of clopidogrel to a $60 \mathrm{mg}$ loading dose of prasugrel [42]. They found higher anti-platelet response in diabetic patients treated with prasugrel, in addition to a superior response profile. In combination, these results suggest that the use of alternative therapies such as ticagrelor or prasugrel could provide superior reductions in platelet reactivity in diabetic patients who do not respond sufficiently to clopidogrel.

Here, we observed that ADP-PGE-induced platelet aggregation positively correlated with fasting blood glucose and HbA1c. We have previously documented a correlation between thrombogenicity and blood glucose levels in type 2 diabetics [11]. Furthermore, we showed that a reduction in $\mathrm{HbA1c}$ level was associated with a reduction in blood thrombogenicity [12]. Angiolillo et al. additionally showed that patients with inefficiently regulated blood glucose exhibited a lower response to clopidogrel, along with increased blood thrombogenicity [31]. However, a significant relationship between ASPI-induced platelet aggregation and fasting blood glucose or HbA1c has not yet been reported. Thus, our results point to an association between actual glucose level and platelet reactivity, although further studies on a larger scale and including assessment of ASPI-induced aggregation are necessary before accurate conclusions can be drawn. Thus, glycemic control might favor a better response to anti-platelet therapies such as clopidogrel in patients with type-2 diabetes.
There are a number of limitations to this study. The low number of patients enrolled resulted in there being fewer than 20 in each of the four groups, with only 13 in the group consisting of diabetic patients receiving the clopidogrel loading dose. A further limitation is that platelet reactivity was not measured prior to initiating clopidogrel therapy. This was because patients were already receiving anticoagulation treatment with ASA.

\section{Conclusions}

In summary, we have examined platelet activity utilizing impedance aggregometry, which represents a simple and fast method to assess inhibition of platelet function. Patients with type-2 diabetes exhibited an increased platelet reactivity compared to patients without diabetes, despite combined treatment with clopidogrel and ASA. Increasing clopidogrel dose was not sufficient for reducing the increased platelet reactivity in patients with type-2 diabetes, highlighting the need to further investigate other anti-platelet drugs in this population.

\section{Abbreviations}

ADP: Adenosine diphosphate; ASA: Acetylsalicylic acid; AUC: Area under the curve; BMI: Body mass index; PGE: Prostaglandin-E; TRAP: Thrombin receptoractivating peptide; TRPC6: Transient receptor potential canonical type 6; VASP: Vasodilator-stimulated phosphoprotein.

\section{Competing interests}

The authors declare that they have no competing interests.

\section{Authors' contributions}

CS and DS participated in the design of the study, carried out the assays, performed the statistical analysis and drafted the manuscript both equally. All authors read and approved the final manuscript.

\section{Acknowledgements}

We thank Franziska Bleis for her technical work.

Received: 18 August 2014 Accepted: 22 January 2015

Published online: 03 February 2015

\section{References}

1. Chesebro JH, Rauch U, Fuster V, Badimon JJ. Pathogenesis of thrombosis in coronary artery disease. Haemostasis. 1997;27:12-8.

2. Massberg S, Schulz C, Gawaz M. Role of platelets in the pathophysiology of acute coronary syndrome. Semin Vasc Med. 2003;3:147-62.

3. Steinhubl SR, Berger PB, Mann III JT, Fry ET, DeLago A, Wilmer C, et al. CREDO Investigators. Clopidogrel for the reduction of events during observation. Early and sustained dual oral antiplatelet therapy following percutaneous coronary intervention: a randomized controlled trial. JAMA. 2002;288:2411-20.

4. Gurbel PA, Bliden KP, Hiatt BL, O'Connor CM. Clopidogrel for coronary stenting: response variability, drug resistance, and the effect of pretreatment platelet reactivity. Circulation. 2003;107:2908-13.

5. van der Heijden DJ, Westendorp IC, Riezebos RK, Kiemeneij F, Slagboom T, van der Wieken LR, et al. Lack of efficacy of clopidogrel pretreatment in the prevention of myocardial damage after elective stent implantation. J Am Coll Cardiol. 2004:44:20-4.

6. Wurtz M, Grove EL. Interindividual variability in the efficacy of oral antiplatelet drugs: definitions, mechanisms and clinical importance. Curr Pharm Des. 2012;18:5344-61.

7. Piorkowski M, Weikert U, Schwimmbeck PL, Martus P, Schultheiss HP, Rauch U. ADP induced platelet degranulation in healthy individuals is reduced by clopidogrel after pretreatment with atorvastatin. Thromb Haemost. 2004;92:614-20. 
8. Piorkowski M, Fischer S, Stellbaum C, Jaster M, Martus P, Morguet AJ, et al. Treatment with ezetimibe plus low-dose atorvastatin compared with higher-dose atorvastatin alone: is sufficient cholesterol-lowering enough to inhibit platelets? J Am Coll Cardiol. 2007:49:1035-42.

9. Combescure C, Fontana P, Mallouk N, Berdague P, Labruyere C, Barazer I, et al. Clinical implications of clopidogrel non-response in cardiovascular patients: a systematic review and meta-analysis. J Thromb Haemost. 2010:8:923-33.

10. Aradi D, Komócsi A, Vorobcsuk A, Rideg O, Tökés-Füzesi M, Magyarliaki T, et al. Prognostic significance of high on-clopidogrel platelet reactivity after percutaneous coronary intervention: systematic review and meta-analysis. Am Heart J. 2010;160:543-51.

11. Rauch U, Crandall J, Osende J, Fallon JT, Chesebro JH, Fuster V, et al. Increased thrombus formation relates to ambient blood glucose and leukocyte count in diabetes mellitus type 2. Am J Cardiol. 2000;86:246-9.

12. Osende Jl, Badimon JJ, Fuster V, Herson P, Rabito P, Vidhun R, et al. Blood thrombogenicity in type 2 diabetes mellitus patients is associated with glycemic control. J Am Coll Cardiol. 2001;38:1307-12.

13. Rauch U, Ziegler D, Piolot R, Schwippert B, Benthake H, Schultheiss HP, et al. Platelet activation in diabetic cardiovascular autonomic neuropathy. Diabet Med. 1999:16:848-52.

14. Rauch U, Schwippert B, Schultheiss HP, Tschoepe D. Platelet activation in diabetic microangiopathy. Platelets. 1998;9:237-40.

15. Shimodaira M, Niwa T, Nakajima K, Kobayashi M, Hanyu N, Nakayama T. Correlation between mean platelet volume and fasting plasma glucose levels in prediabetic and normoglycemic individuals. Cardiovasc Diabetol. 2013;12:14.

16. Kassaian SE, Goodarzynejad H, Boroumand MA, Salarifar M, Masoudkabir F, Mohajeri-Tehrani MR, et al. Glycosylated hemoglobin ( $\mathrm{HbA} 1 \mathrm{c})$ levels and clinical outcomes in diabetic patients following coronary artery stenting. Cardiovasc Diabetol. 2012;11:82.

17. Geisler T, Anders N, Paterok M, Langer $H$, Stellos K, Lindemann S, et al. Platelet response to clopidogrel is attenuated in diabetic patients undergoing coronary stent implantation. Diabetes Care. 2007;30:372-4.

18. Angiollo DJ, Fernandez-Ortiz A, Bernardo E, Ramírez C, Sabaté M, JimenezQuevedo P, et al. Clopidogrel withdrawal is associated with proinflammatory and prothrombotic effects in patients with diabetes and coronary artery disease. Diabetes. 2006:55:780-4.

19. Dynabyte Informationssysteme GmbH. (http://www.multiplate.net).

20. Payne CD, Li YG, Small DS, Ernest II CS, Farid NA, Jakubowski JA, et al. Increased active metabolite formation explains the greater platelet inhibition with prasugrel compared to high-dose clopidogrel. J Cardiovasc Pharm. 2007;50:555-62.

21. Stellbaum C, Ayral Y, Morguet A, Schultheiss H-P, Rauch U. Doubling the clopidogrel dose in patiens with reduced responsiveness to the standard dose is associated with a limited effectiveness as evaluated by impedance aggregometry. Cardiovasc Revasc Med. 2012;13:159-66.

22. Mortensen SB, Larsen SB, Grove EL, Kristensen SD, Hvas A-M. Reduced platelet response to aspirin with coronary artery disease and type 2 diabetes mellitus. Thromb Res. 2010;126:e318-22.

23. Erlinge D, Varenhorst C, Braun OÖ, James S, Winters K, Jakubowski J, et al. Patients with poor responsiveness to thienopyridine treatment or with diabetes have lower levels of circulating active metabolite, but their platelets respond normally to active metabolite added ex vivo. JACC. 2008:52:1968-77.

24. Schönbeck U, Varo N, Libby P, Buring J, Ridker PM. Soluble CD40L and cardiovascular risk in women. Circulation. 2001:104:2266-8.

25. Ridker PM, Cushman M, Stampfer MJ, Tracy RP, Hennekens CH. Inflammation, aspirin, and the risk of cardiovascular disease in apparently healthy men. New Eng J Med. 1997;336:973-9.

26. Geisler T, Mueller K, Aichele S, Bigalke B, Stellos K, Htun P, et al. Impact of inflammatory state and metabolic control on responsiveness to dual antiplatelet therapy after PCl: prognostic relevance of residual platelet aggregability in diabetics undergoing coronary interventions. Clin Res Cardiol. 2010;99:743-52.

27. Rosiak M, Postula M, Kaplon-Cieslicka A, Kondracka A, Trzepla E, Czlonkowski $A$, et al. Effect of ASA dose doubling versus switching to clopidogrel on plasma inflammatory markers concentration in patients with type 2 diabetes and high platelet reactivity: The AVOCADO study. Cardiol J. 2013;20:545-51.
28. Gresner P, Dolnik M, Waczulikova I, Bryszewska M, Sikurova L, Watala C. Increased blood plasma hydrolysis of acetylsalicylic acid in type 2 diabetic patients: a role of plasma esterases. Biochim Biophys Acta. 2006;1760:207-15.

29. Kaplon- Cieslicka A, Postula M, Rosiak M, Peller M, Kondracka A, Serafin A et al. Younger age, higher body mass index and lower adiponectin concentration predict higher serum thromboxane $B_{2}$ level in aspirin-treated patients with type-2 diabetes: an observational study. Cardiovasc Res. 2014;13:112-23.

30. Miller SR, Littenberg B, MacLean CD. Prevalence of antiplatelet therapy in patients with diabetes. Cardiovasc Diabetol. 2005;4:18.

31. Angiolillo DJ, Fernandez-Ortiz A, Bernardo E, Ramírez C, Sabaté M, JimenezQuevedo $\mathrm{P}$, et al. Platelet function profiles in patients with type 2 diabetes and coronary artery disease on combined aspirin and clopidogrel treatment. Diabetes. 2005;50:2430-5.

32. Tschoepe D, Rauch U, Schwippert B. Platelet-leukocyte-cross-talk in diabetes mellitus. Horm Metab Res. 1997;29:631-5.

33. Liu D, Maier A, Scholze A, Rauch U, Boltzen U, Zhao Z, et al. High glucose enhances transient receptor potential channel canonical type 6-dependent calcium influx in human platelets via phosphatidylinositol 3-kinase-dependent pathway. Arterioscler Thromb Vasc Biol. 2008;28:746-51.

34. Rauch U, Antoniak S. Tissue factor-positive microparticles in blood associated with coagulopathy in cancer. Thromb Haemost. 2007;97:9-10.

35. Bobbert P, Eisenreich A, Weithäuser A, Schultheiss HP, Rauch U. Leptin and resistin induce increased procoagulability in diabetes mellitus. Cytokine. 2011;56:332-7.

36. Bobbert P, Rauch U, Stratmann B, Goldin-Lang P, Antoniak S, Bobbert T, et al. High molecular weight adiponectin correlates positively with myeloperoxidase in patients with type 2 diabetes mellitus. Diabetes Res Clin Pract. 2008:82:179-84.

37. Pepke W, Eisenreich A, Jaster M, Ayral Y, Bobbert P, Mayer A, et al. Bivalirudin inhibits periprocedural platelet function and tissue factor expression of human smooth muscle cells. Cardiovasc Ther. 2013;31:115-23.

38. Laine M, Frère C, Toesca R, Berbis J, Barnay P, Pansieri M, et al. Ticagrelor versus prasugrel in diabetic patients with an acute coronary syndrome. A pharmacodynamic randomised study. Thromb Haemost. 2014;111:273-8.

39. Alexopoulos D, Xanthopoulou I, Mavronasiou E, Stavrou K, Siapika A, Tsoni E, et al. Randomized assessment of ticagrelor versus prasugrel antiplatelet effects in patients with diabetes. Diabetes Care. 2013;36:2211-6.

40. Wallentin L, Becker RC, Budaj A, Cannon CP, Emanuelsson H, Held C, et al. Ticagrelor versus clopidogrel in patients with acute coronary syndromes. N Engl J Med. 2009;361:1045-57.

41. Sibbing D, von Beckerath O, Schömig A, von Beckerath N. Diabetes mellitus and platelet function after administration of aspirin and a single $600 \mathrm{mg}$ dose of clopidogrel. J Thromb Res Haemost. 2006;4:2566-8.

42. Angiolillo DJ, Badimon JJ, Saucedo JF, Frelinger AL, Michelson AD, Jakubowsk $J A$, et al. A pharmacodynamic comparison of prasugrel vs. high-dose clopidogrel in patients with type 2 diabetes mellitus and coronary artery disease: results of the Optimizing anti-Platelet Therapy In diabetes MellitUS (OPTIMUS)-3 Trial. Eur Heart J. 2011;32:838-46.

\section{Submit your next manuscript to BioMed Central and take full advantage of:}

- Convenient online submission

- Thorough peer review

- No space constraints or color figure charges

- Immediate publication on acceptance

- Inclusion in PubMed, CAS, Scopus and Google Scholar

- Research which is freely available for redistribution 